\title{
A Case Study on Kenyan Female Students' High Post-Primary Drop-out Rate
}

\author{
Yuwei Bai \\ London School of Economics and Political Science, Social Policy Department, London, UK \\ Corresponding author. Email: gaoming@cas-harbour.org
}

\begin{abstract}
This essay looks at the topic of gender equality in education by focusing on Kenyan female high post-primary school drop-out rate. Through field research in Nairobi, Kenya, the author identified the main socioeconomic factors that constraints Kenyan females from continuing education. The factors are categorised into (1) The Lack of Family Financial Support; (2) Entrenched Culture of Early Marriage, Pregnancy and FGM; and (3) Subject and Career Choice Brought by Gender Role. Accordingly, measures which empower female with the right to education is proposed. Society as a whole should put in effort together to eliminate the gender discrimination and barriers. Also, measures ensuring female rights in education in Kenya should be taken.
\end{abstract}

Keywords: Kenya, Edudation, Inequality, Women

\section{INTRODUCTION}

Such is the profound magnitude of education, that any society is irrefutably and eventually the product of a conscious and continuous educational process. As the global society seeks to address the most consequential issues of our generation, the United Nation announces the Sustainable Development Goals (SDGs), whose fourth initiatives "Quality Education" reads: "Ensure inclusive and equitable quality education and promote lifelong learning opportunities for all;" whereas, the associated target 4.5 proclaims that "by 2030 , eliminate gender disparities in education and ensure equal access to all levels of education and vocational training for the vulnerable, including persons with disabilities, indigenous peoples and children in vulnerable situations." By educating and empowering the next generation and especially those who are vulnerable, social inequalities should be tackled from every aspect; and thus, making sure education is fair and equal becomes the first and foremost task.

Yet, in most cases regarding gender disparities in education, education policies and legal efforts have been largely concentrated on ensuring equal access to education for both boys and girls while ignoring those more fundamental, underlying factors that are deeply embedded in socioeconomic conditions. To elaborate and emphasise how structural issues could inflict colossal backlash against policy initiatives, this essay attempts to conduct a case study on Kenyan female education, particularly on its post-primary school drop-out rate, the underlying reasons, and viable solutions. It is evident that Kenyan male and female students enjoy rather equal opportunities when accessing primary school education. However, female students are deprived of their promised education due to factors that are largely gender-related, and hence, there exists a disturbingly high drop-out rate of female students in Kenyan Post-primary Schools.

\section{RESEARCH BACKGROUND-FEMALE HIGH DROP-OUT RATE IN KENYAN POST-PRIMARY SCHOOLS}

Gender disparities in Kenyan education emerge from structural obstacles that pose economic, social, cultural, and political challenges against female students. As empowering females through education has become one of the most important agendas in Kenya, access to primary education is not the major gender problem due to advancements of the Kenyan education system. Data show that the gap between male and female enrollments in primary education has become insignificant in recent years. According to UNESCO, in 2014, the percentage of Kenyan female students who finished primary school was $87 \%$, outweighing that of male, which was at $81 \%$. The lower secondary completion rate for females was $75 \%$, while for males it was at $66 \%$. This finding 
indicates that education opportunities were provided rather equally at the stage of primary education. However, the upper-secondary completion rate for women dropped critically to $39 \%$. All female completion rates above lower secondary education were lower than those for males, and the indexes decreased continuously throughout the later education stages.[1] As a result, though both male and female students enjoy equal opportunities for education at the primary education stage, there must be other gender factors that indirectly contribute to female students' high post-primary drop-out rate, and consequently, that the average years of education for females were lower than males.

\section{CASE STUDY IN NAIROBI, KENYA}

The author conducted a field research in 2019 in Nairobi, the capital of Kenya, with 3 peers from China House.[2] The focus was on the underlying reasons behind the female post-primary drop-out rate. The author interviewed a number of local communities and NGOs that focus on women empowerment, in order to collect information on the status quo of female education. Joseph Saya, who was studying Electrotechnics at a vocational school in Nairobi, explained that one of the reasons they attended vocational schools was not because of financial constraints, but because many students could not pass the university entrance exam. He pointed out that the exams were difficult to pass, and the teaching quality at school was hardly eligible. Education resources were scarce and physical facilities were inadequate, even in central areas of Nairobi, resulting in students' poor performance. Mackatiani's (2017) research in Kenyan second largest County, Kakamega, found out that "28 percent of primary schools had inadequate administration facility; 67 percent had inadequate classrooms; 84 percent of the primary schools had inadequate latrines; 67 percent had inadequate tables and chairs." [3]

Whereas, lack of education resources affects both male and female students, which suggests that higher drop-out rate among female students are caused by other factors. The author continued our interviews in areas that were socioeconomically inferior, such as Kibera (the largest slum in Nairobi) and the Maasai Tribe, meeting with local representatives from various backgrounds and NGO specialists. Based on their responses regarding female schooling experiences in Kenya, the author concluded that there were three major aspects that led to a higher female drop-out rate: firstly, financial constraint; secondly, early marriage, pregnancy and FGM; and thirdly, subject choice.

\section{KEY FINDINGS}

\subsection{The Lack of Family Financial Support}

Poverty was almost unanimously agreed among interviewees, as the first and foremost incentive leading to students' drop-out. Social stereotypes often picture women engaging in housework and childcare, and thus, limit their career-planning options as well as the vision for long-term development. On the other hand, men as the 'breadwinner' are conventionally assumed to be more likely to receive higher rewards from education, especially at higher education stages. This is actually a "post hoc, ergo propter hoc" logic fallacy, that education investments are allocated to men in the first place, which then led to higher incomes among men than women. Meanwhile, many girls quit school early in order to support their families by doing low-income part-time jobs or start their own small business.

One of the interviewees, Peninnah, owned a six square-meter saloon in Kibera with two employees. She started a small business group with her female friends, seven of whom dropped out of school either after finishing primary or secondary education. Since opening their business, the living conditions of Peninnah and her friends had been improved, despite not completing secondary education. She also raised chickens as her avocation. Years of hard work enabled her to sustain her four children's education to tertiary education. Peninnah and her business friends were successful examples of how dropping out of school could earn money and support their family. However, it is uncertain whether continuing education would have brought them even higher income, and their success was not at all a prevalent phenomenon in Kibera. The majority of the females interviewed lacked the skills and economic base to start up and expand their businesses due to their early drop-out and limited savings-they could not even afford the informal training. Besides, uniform costs and daily lunch fees could be quite a burden for students without financial support. Uniforms are a "strictly enforced tradition"[4] in Kenyan schools. From a cohort randomised evaluation done by Duflo et al. (2015) in Kenya, the intervention of free uniforms made a great difference to girls' drop-out rate - drop-out rate for girls who received free uniform decreased 16.5 percent [5]. While the limited family income is tilted to boys' education rather than girls, the additional costs of schooling further minimise the opportunity for girls to continue their studies when the family is in need of internal support.

\subsection{Entrenched Culture of Early Marriage, Pregnancy and FGM}

Early pregnancy is a serious problem in Kenya, another major cause of girl's high drop-out rate. 
According to the Kenyan demographic and health survey conducted in 2014, "eleven percent of women age 15-19 are currently married, as compared with just 1 percent of men age 15-19."'[6] These young mothers have to take care of themselves during pregnancy, give birth to their children and raise them. This complicated long term process greatly affects girls' education at school. Once they leave school, it is hardly possible for them to return after delivery as it is hard to catch up. Part of early pregnancy results from early marriage, which is entrenched in Kenyan tradition and culture. The situation is worse in rural areas. Unwealthy Maasai families prioritise their sons' education and marry off the daughters since girls cannot contribute much to the family. Africila, the founder of the Maasai girls' rescue school, has witnessed many Masai girls who were betrothed at very young ages. "Their parents decide for them, and I wanted to help them, tell them they have other choices," she said.

Female Genital Mutilation (FGM), also known as female circumcision, is another traditional culture that involves the partial or total cutting or removal of female genitalia. Many girls are forced to endure the FGM, usually at the end of primary school. FGM has no health benefits while the poor medical condition brings negative side effects to girls' health, such as severe bleeding, infections, infertility, and urination problems.[7] Besides the physical damage to health, FGM also have severe negative impacts on female mental health. Africila said that, "They are treated as a woman after circumcision, and men can approach her for sex. There is no rape if a woman is circumcised." Sexual harassment at school come along with FGM, and girls are at a very disadvantageous place, so they may choose to drop out. The physical and psychological effects of FGM on girls are detrimental.

\subsection{Subject and Career Choice Brought by Gender Role}

Female students' subject choices tend to focus on humanities or social sciences during higher education. "In 2017, there were 21,400 professional women employed in the science and technical fields...even though their male counterparts were still more than double at 52,400 professionals."[8] The fact is consistent with the Chairman of the Department of Information Technology, who said that female students only constitute approximately $25 \%$ of the population in the school of computing \& IT at the Muranga University of Technology. Female students' subject choices are mainly in the fields that come with lower income and little influence. Their superiors at work who they look up to are predominantly males. Interview results show that the experience of competition and discrimination of females in the labour market is passed on to the young girls, implying that time spent in higher education is unworthy. The alternative for females is to learn actual skills and start working at an earlier age. Those who have financial support also prefer vocational training to university.

\section{MEASURES ENSURING FEMALE RIGHTS TO EDUCATION IN KENYA}

\subsection{Programmes Working on Female's Empowerment}

Local programmes advocating women empowerment have been seeking various ways to support female education. Founded in 2008, Team Kenya registered at Fundraising Regulator as a charity, and has succeeded in changing the lives of over 20,000 teenage girls. Team Kenya recognised the burden of additional costs on many families, and identified structural social problems such as early marriage and pregnancy. They established connections with twelve local primary schools and provided a series of supporting programmes for female students, including but not limited to: academic mentoring; individual support, training, guidance and counselling; extra-curricular activities that boost confidence and self-esteem, social worker support for victims of Gender-Based Violence (GBV); confidence-building extra-curricular activities; and training of parents and teachers. 19 girls from their scholarship programme had graduated in 2017, and their mothers were then able to support them without outside help. Thus, the team decided to "slowly replace secondary school and university sponsorship programme with table banking, agricultural training and enterprise for mothers."'[9] However, the strength of assisting girls in school financially is still very limited in number. Also, Team Kenya work with primary schools only, while girls' drop-out rate increase dramatically in secondary schools, which are the education stage where girls are more likely to get married or pregnant.

International organisations had also worked on empowering women outside of school intellectually and economically. Women Empowerment in Kenya was originally founded in Germany in 2017, their aim is "to provide young vulnerable women in Kenya with education and starting capital to help improve their life and the life of their children." They provide training on managing daily lives such as family planning and personal hygiene, and also economic training on agriculture, saloon work, or tailoring skills. Working in groups, women are able to benefit from building networks, exchanging ideas and experiences, and to gain confidence through teamwork. Another organisation, CARE, originated in USA, "was one of the first such organisations to set up base in a new Kenya."[10] They are working on numerous projects that offer loans, productive assets, technologies, and training. 


\subsection{Improve Collaboration of Government and Organisations to Increase Funding on Education}

It is important to respect the girls and their parents' choice to either attain secondary and tertiary education or drop out and attend vocational training. Support is needed for both paths. On resolving poverty and financial constraints, disadvantaged Kenyan females have been trapped in a vicious cycle. Education is the way to empower themselves and improve social mobility, but they do not have enough financial support to stay in schools or attend vocational training. Thus, they lack the knowledge and skills necessary to work and to earn income, and remain impoverished. Free workshops and group training has led to some progress in female skillset build-up, but skills taught are too specialised and limited. Cutting and stylising hair is insufficient for running a salon business, which still requires accounting and managing skills. Additionally, females who attend the same workshops often find themselves competing against each other. For example, the street where Peninnah's salon is located has more than 8 salons, forming a competitive market. Poverty issues take time, but supporting a girl today will make an entire family self-reliant in the following years. An educated and dependent mother will have a multiplier effect on society, as she will ensure equal education opportunities for her children, whether boys or girls. The Kenyan government needs to build more post-primary schools, especially in rural areas, to solve the problem of the long distance to school. Education should be free and the additional fees should be minimised and covered by scholarships. That said, funding is always the principal concern.

According to the World Bank, "Technical and Vocational Education and Training (TVET) in African countries has been under invested and faced considerable challenges, with little enrollment rates, low quality and relevance across most countries."[11] From the data in 2018, Kenya's "technical and vocational education and training (TVET) gets a very small proportion (below 5\%) of the education budget," while the "unemployment among youth aged 15-24 years stands at 22.2\%." [12] Although the government expenditure on TVET has doubled from 2016-2018, the proportion and actual amount are still meagre. It is necessary to increase funding to expand and diversify training programmes, advance vocational curriculum, and make these workshops interest-driven and fulfilling. The transition from a vicious cycle into a virtuous cycle for Kenyan females requires vast investment at the early stage. Education, being the foundation and catalyst for development, should be seen as the priority of Kenyan governments. While the government and NGOs are and will remain the major sources of funding, education should constitute a larger proportion of government spending; and governmental collaboration with local and international NGOs should be articulated and reinforced. The overall aim is to build more post-primary schools, improve teacher training and school facilities, and expand vocational education so that the female students in schools and out of schools could use all the help they could get.

\subsection{Strengthen the Enforcement of Legislation and Regulation on Early Marriage, Early Pregnancy, and FGM}

Since the traditions of FGM and early marriage have lasted a long time in Kenyan history, it will be discouraging and difficult to eradicate such practice without legislation and community support. In 2011, Kenya passed the Prohibition of Female Genital Mutilation Act, making FGM illegal.[13] However, FGM is still a physical threat and mental suffering for many Kenyan girls. The Kenyan Children act in 2001 also made early marriage before 18 years old illegal.[14] Anti-FGM and anti-early marriage activists and organisations should advocate the benefits of abolishing FGM for females and collaborate with law enforcement and other governmental institutions. Their work needs to be stretched to the rural areas, slums and tribes where such outdated and deleterious practices as FGM and early marriages are still most prevalent. For girls who have already experienced FGM and married early, mental support by communities could be very helpful for building their confidence and self-esteem. The government must enforce and uphold the laws on FGM and early marriage, with more strict regulations and serious punishments.

\subsection{Implement Strategies to Ensure Gender Balance in STEM Subjects}

From the second Edition of Education and Training Sector Gender Policy published by the Kenyan Ministry of Education Science and Technology in 2015, the ongoing policies mainly focus on tackling gender inequality in access to education, opportunity at schools and quality education [15]. However, the main problem for Kenyan females is not that education is inaccessible, but females are disadvantaged by external and structural forces and, therefore, forced out of school with limited opportunities. In Chapter 6: Nurturing and mentoring, policy statement 6.4 claims to "Facilitate gender-balanced participation in STEM and Innovation in academic programmes." The strategies provide a feasible roadmap for encouraging female students to broaden their options and vision and resolving high drop-out rate due to subject choice. The effectiveness still needs to be evaluated by future research, and regulations and supervisions are necessary. 


\section{CONCLUSION}

Although female students in Kenya enjoy rather equal access to primary education, gender-related structural disadvantages burden them with socioeconomic and cultural predicaments, which lead to a high drop-out rate among Kenyan female students during post-primary education. Poverty, in the first place, traps women into a vicious circle where they have to struggle against impoverishment, benightedness, and uninformed gender stereotypes. The ensuing cultural ramifications--FGM, early marriage, and pregnancy--inflict both physical and mental damages to women, and along with subject choice, potentially shorten the years of schooling for Kenyan female students. Additionally, as any one of these issues naturally implicates another, UN SDG 4 Quality Education becomes the tangible thread that could ultimately resolve the same structural obstacles against SDG 1 No Poverty and SDG 5 Gender Equality.

The respective roles of and collaboration among the government, NGOs, and activists should be emphasised. The Kenyan government should reinforce the laws prohibiting FGM and early marriage, unswervingly increase spending on building secondary and tertiary schools, including vocational schools, and provide adequate facilities and teacher training. Government-funded scholarships in public schools can include more female students or provide benefits such as free lunch. NGOs should continue their work on providing economic, vocational and health supports through different types of long-term projects, and introduce more diversity in their curriculum. Activists and researchers play an instrumental role by providing feedback about the execution of laws and projects to policymakers. Overall, all three important sectors must put effort into raising the social awareness on gender equality, which is the primary cause of structural discrimination. The education quality in Kenya has not yet achieved SDG 4 and its associated targets, while there still exists numerous problems and challenges which entail thorough research and reforms in the future. Nairobi, as the capital of Kenya, has already concentrated most educational resources and provided the highest level of education nationally. Other counties in Kenya, as well as many African countries and developing countries worldwide, face even more severe conditions to meet the quality education goal. The conventional discourse creates long-lasting structural obstacles which root in society and cause policy backlashes against social progress. This essay hopes to offer an inspiring perspective that promotes fundamental reforms against structural impediments that could truly leave some heartfelt legacies to the peoples in need.

\section{REFERENCES}

[1] World Inequality Database on Education • World Inequality Database on Education. Retrieved 16 April 2021, from

https://unesco-wide-production.herokuapp.com.

[2] Bai, Y., Hu, C., Cao, X., \& Zeng, T. (2019). High Dropout Rate of Kenyan Women after Primary School: Can China Become Part of the Solution? Retrieved 16 April 2021, from https://chinaafricaproject.com/student-xchange/hig h-dropout-rate-of-kenyan-women-after-primary-sch ool-can-china-become-part-of-the-solution/.

[3] Mackatiani, C. (2017). INFLUENCE OF PHYSICAL FACILITIES ON QUALITY PRIMARY EDUCATION IN KENYA IN POST UPE AND EFA ERA. European Journal Of Education Studies, 3(5). doi: 10.5281/zenodo.573711.

[4]https://borgenproject.org/problems-dressing-successkenyan-schools/.

[5] Duflo, E., Dupas, P., \& Kremer, M. (2015). Education, HIV, and Early Fertility: Experimental Evidence from Kenya. American Economic Review, 105(9), 2757-2797. doi: 10.1257/aer.20121607

[6] Kenya Demographic and Health Survey 2014. (2015). Retrieved 16 April 2021, from http://www.nutritionhealth.or.ke/wp-content/upload s/Downloads/Kenya\%20Demographic\%20and\%20 Health\%20Survey\%20KDHS\%20Report\%202014. pdf.

[7] Edwards, C. (2016). Why Do Girls In Kenya Drop Out Of School?. Retrieved 16 April 2021, from https://www.linkedin.com/pulse/why-do-girls-keny a-drop-out-school-caitlin-edwards.

[8] NYAYIEKA, I. (2019). Women in Kenya closing gender gap in science and tech. Retrieved 16 April 2021, from

https://www.businessdailyafrica.com/datahub/Wom en-in-Kenya-closing-gender-gap-in-science-/38154 18-4975340-a5dkskz/index.html.

[9] Girls' Education - Team Kenya. Retrieved 16 April 2021, from https://www.teamkenya.org.uk/girls-education/.

[10] CARE Kenya - Women and Girls Economic Empowerment. Retrieved 16 April 2021, from https://www.care.or.ke/index.php/what-we-do/wom enempowerment.

[11] Technical and Vocational Education and Training: Lessons from China. (2018). Retrieved 16 April 
2021, from

https://www.worldbank.org/en/news/feature/2018/ 10/30/technical-and-vocational-education-and-train ing-lessons-from-china

[12] Ngware, M. (2019). Where Kenya is spending money on education -- and what's missing. Retrieved $21 \quad$ April 2021, from https://theconversation.com/where-kenya-is-spendi ng-money-on-education-and-whats-missing-11939 3

[13] PROHIBITION OF FEMALE GENITAL MUTILATION ACT. (2011). Retrieved 16 April 2021, from
http://kenyalaw.org/kl/fileadmin/pdfdownloads/Act s/ProhibitionofFemaleGenitalMutilationAct_No32o f2011.pdf

[14] The Children ACT. (2010). Retrieved 16 April 2021, from https://bettercarenetwork.org/sites/default/files/The \%20Children\%27s\%20Act\%2C\%20Kenya_0.pdf

[15] Education and Training Sector Gender Policy. (2015). Retrieved 16 April 2021, from https://planipolis.iiep.unesco.org/sites/default/files/r essources/kenya_education_training_gender_policy .pdf 